\title{
Orthodontic Intrusion of over Erupted Permanent Maxillary Molars Using Temporary Anchorage Devices
}

\author{
Mohammad Jaradat ${ }^{*}$, Waddah Arda² \\ ${ }^{1}$ Department of Orthodontics \& Pedodontics, Faculty of Dentistry, Arab American University of Palestine, Jenin, Palestine \\ ${ }^{2}$ Oral and Maxillofacial Surgeon, Private Clinic, Palestine \\ Email: ^mojaradat@hotmail.com, Mohammed.jaradat@aaup.edu
}

How to cite this paper: Jaradat, M. and Arda, W. (2019) Orthodontic Intrusion of over Erupted Permanent Maxillary Molars Using Temporary Anchorage Devices. Open Journal of Stomatology, 9, 95-101. https://doi.org/10.4236/ojst.2019.95010

Received: April 3, 2019

Accepted: May 10, 2019

Published: May 13, 2019

Copyright () 2019 by author(s) and Scientific Research Publishing Inc. This work is licensed under the Creative Commons Attribution International License (CC BY 4.0).

http://creativecommons.org/licenses/by/4.0/

\section{(c) (i) Open Access}

\begin{abstract}
In most cases, damaged mandibular molars result in over eruption of the opposing maxillary molars. This by itself constitutes a complicated clinical scenario; since the rehabilitation of the edentulous mandibular space usually requires a pre-prosthetic intervention. Multiple treatment options are valid and the choice depends primarily on the severity of the problem. Orthodontic molar intrusion is one of these options. This case report shows how the supra erupted maxillary permanent molars were intruded with the help of temporary anchorage devices placed inter-radicularly between the maxillary posterior teeth. A total of nine months was enough to complete the treatment. Following the orthodontic molar intrusion, the lower edentulous spaces were restored with dental implant supported prosthesis in order to establish a stable functional occlusion.
\end{abstract}

\section{Keywords}

Molar Intrusion, Temporary Anchorage Devices, Trans Palatal Bar, Conventional Dental Implants

\section{Introduction and Literature Review}

In most cases, damaged mandibular molars result in over eruption of the opposing maxillary molars. This by itself constitutes a complicated clinical scenario; since the rehabilitation of the edentulous mandibular space usually requires an intervention preceding the prosthesis placement. Multiple treatment options are valid and the choice depends primarily on the severity of the problem [1]. The first clinical report to intrude the teeth using the temporary anchorage de- 
vices was in 1983 when Creekmore and Eklund used a titanium screw fixed in the anterior nasal spine to intrude the maxillary incisors [2]. Armbruster et al. (2003) intruded the posterior tooth in a noninvasive way using a combination of elastics with a clear Essex appliance [3]. In 2007, Kravitz et al. used a minimally invasive, noncompliant clinical procedure for maxillary molar intrusion with the help of orthodontic miniscrews [4].

\section{Case Report}

22 years old Palestinian female was referred to the orthodontic clinic for consultation regarding the over erupted permanent maxillary molars (teeth numbered 16, 17, 26 and 27) [Figure 1].

\section{Past dental history:}

The past dental history included:

1) placement of an upper fixed ceramic fused to metal bridge extending from the maxillary right canine (13) to the maxillary left canine (23) [Figure 2].

2) Teeth number $(14,24,25)$ were damaged [Figure 3 ].

3) Teeth number $(46,47,36)$ were damaged [Figure 3 ].

4) Damaged lower left second permanent molar (37) with peri-apicallesion [Figure 3].

Medical condition: The patient was not suffering from any medical condition or taking any medication.

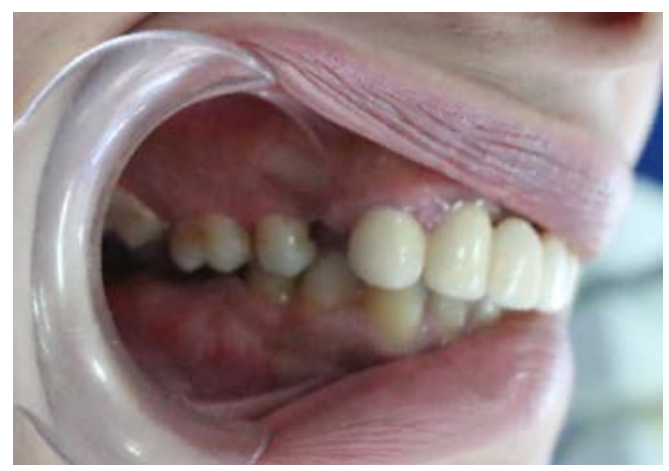

Figure 1. Over erupted maxillary first and second permanent molars (teeth number 16, 17,26 and 27).

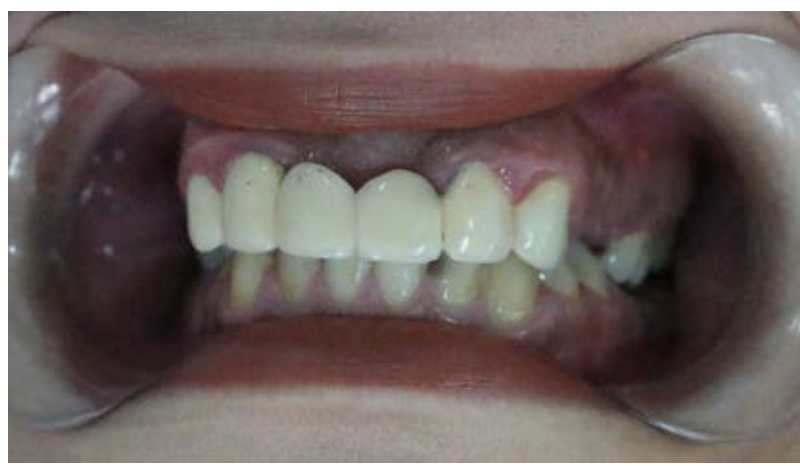

Figure 2. Ceramic fused to metal bridge on anterior front teeth. 


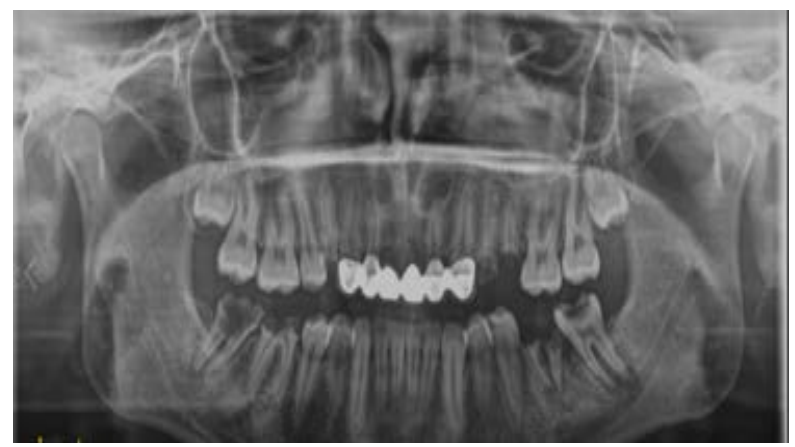

Figure 3. OPG showing the heavily destroyed teeth.

\section{Diagnosis and etiology:}

The patient presented with class ii div 1 incisor relationship on skeletal base ii (BSI Classification system) complicated by:

- An increased overjet (4 mm),

- Increased overbite,

- The presence of multiple damaged permanent teeth (teeth numbered 24, 25, $14,36,37,46$ and 47 ),

- Over erupted upper first and second permanent molars.

Treatment objectives: the treatment aimed to achieve the following goals:

1) Intrusion of the maxillary first and second permanent molars,

2) Elimination of any need for endodontic treatment and invasive crown reduction of the maxillary permanent first and second molars,

3) Facilitate the placement of dental implants at the sites of the lower first and second permanent molars to establish a functional posterior occlusion,

4) Replace the damaged upper premolars with dental implant supported prosthesis.

Treatment Plan: a comprehensive upper and lower fixed orthodontic appliance was not an option because the patient had a ceramic fused to metal bridge extending from upper left permanent canine to the right permanent canine. So, a sectional orthodontic appliance consisting of four molar bands placed on the permanent maxillary first and second molars was used to intrude these supra erupted molars.

\section{Treatment Progress}

Before the start of orthodontic molar intrusion, all damaged teeth were extracted (teeth numbered 24, 25, 14, 36, 37, 46 and 47) [Figure 4].

In order to intrude the maxillary 1st permanent molars, two self-tapping orthodontic mini-screws (Vector TAS; Oromco) of $1.4 \mathrm{~mm}$ (diameter) and $8 \mathrm{~mm}$ (length), were threaded (two months following the teeth extraction) in the maxillary buccal dento-alveolar area mesial and distal to the first permanent molars. Trans-palatal bar with $0.9 \mathrm{~mm}$ diameter (Figure 5) extending between the contralateral maxillary first permanent molars $(16 \& 26)$ was used [5]. The placement of trans-palatal bar aimed to ensure bodily molar intrusion without any buccal flaring of the maxillary molars during the intrusion process. 


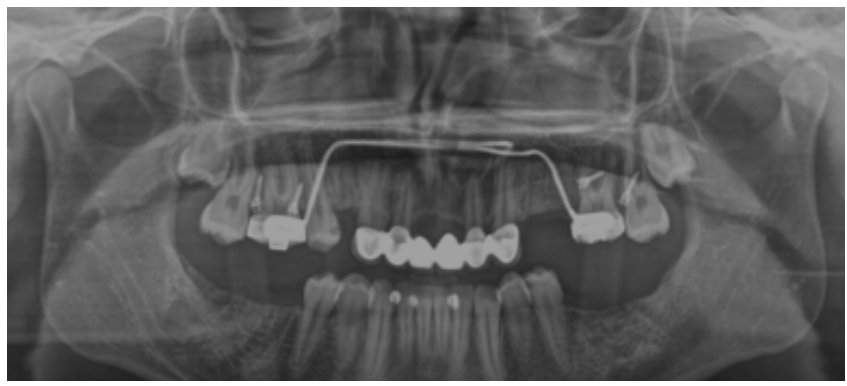

Figure 4. OPG following extraction of heavily destroyed teeth and the placement of Temporary Anchorage Devices and Trans-Palatal Arch in the upper arch.

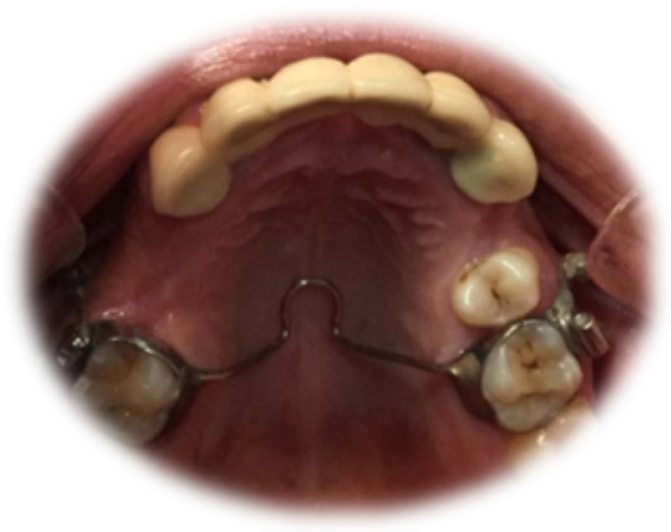

Figure 5. Trans-palatal bar extending between 1st permanent maxillary molars (teeth number 16, 26).

The mini screws were inserted interdentally between the second premolar and first molar and between the first and second permanent molars just below the level of the muco-gingival junction. All mini screws were placed using only topical anesthesia.

The mini screws were loaded two weeks following their placement. The force level was $100 \mathrm{~g}$ via a closed elastic power chain (American orthodontic company) Figure 6. During the activation (every 2 weeks) period, the chain was cut, leaving one remaining link every visit.

Conventional dental implants were inserted at the following sites six months following the extraction of the damaged teeth.

- Lower first and second permanent molars (36, 37, 46 and 47).

- Maxillary first and second left premolars $(24,25)$.

After four months of active treatment, sufficient first permanent molar intrusion was observed [Figure 7]. In order to intrude the second maxillary molars, an additional mini screw was placed distal to the maxillary second permanent molars on both sides [Figure 8]. After three months of active treatment, sufficient 2nd permanent molar intrusion was achieved.

\section{Results}

Following the three-month Osseo integration period, ceramic fused to metal 

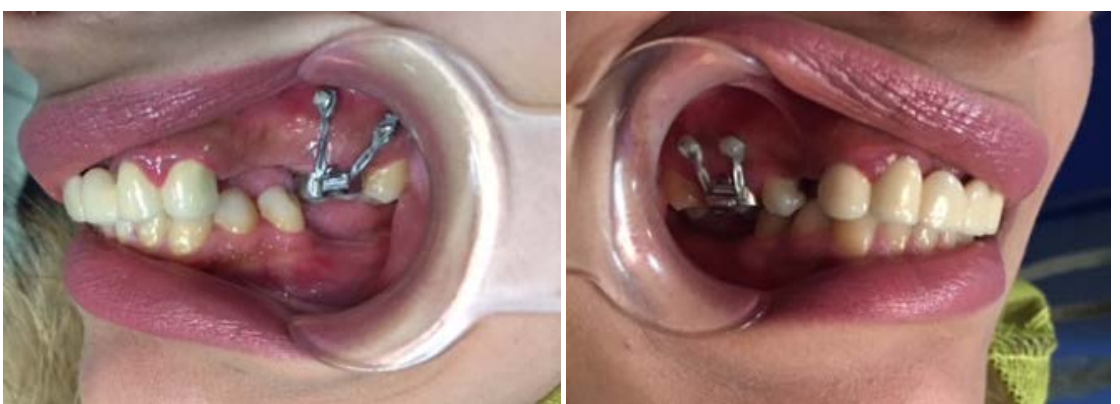

Figure 6. First permanent molar intrusion using mini screws.
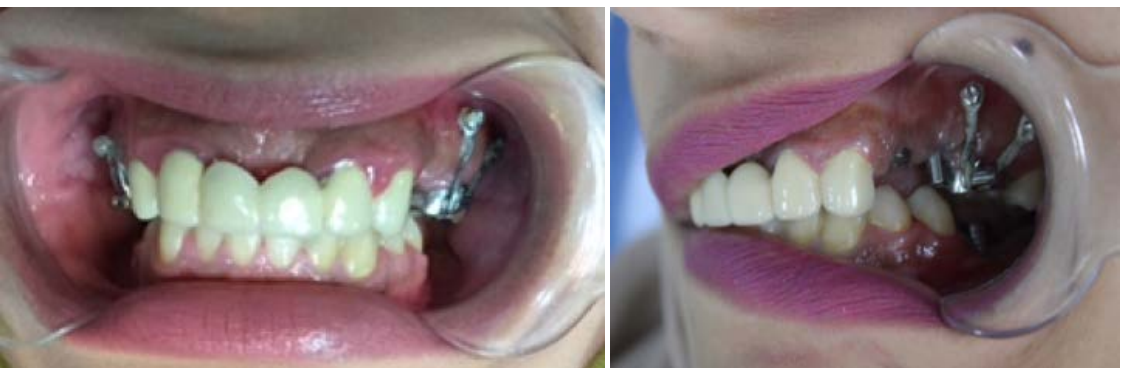

Figure 7. Sufficient 2nd permanent molar intrusion.

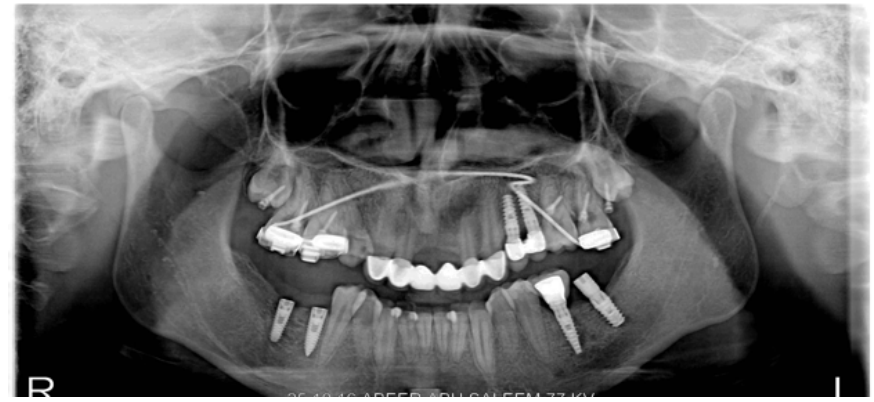

Figure 8. OPG showing the intrusion of maxillary 2nd molars (teeth number 17, 27).

crowns were placed and cemented over the dental implants and then the mini screws were removed [Figure 9].

No screw loosening was reported during the intrusion process and a total of nine months was needed in order to achieve the treatment goals. Maxillary molar intrusion was achieved with the help of orthodontic mini implants and a stable functional occlusion was achieved through the placement of Osseo integrated implant supported prosthesis.

\section{Discussion}

Over erupted maxillary molars pose a clinical problem, different treatment modalities were suggested in order to solve such a problem; Enamelo-plastycan effectively reduce occlusal discrepancy in a moderately extruded tooth where about $1-2 \mathrm{~mm}$ of enamel can be reduced [1]. Another treatment modality for supra erupted molars is Intentional root canal treatment for teeth which need drastic occlusal reduction [6]. A more conservative approach to manage such 

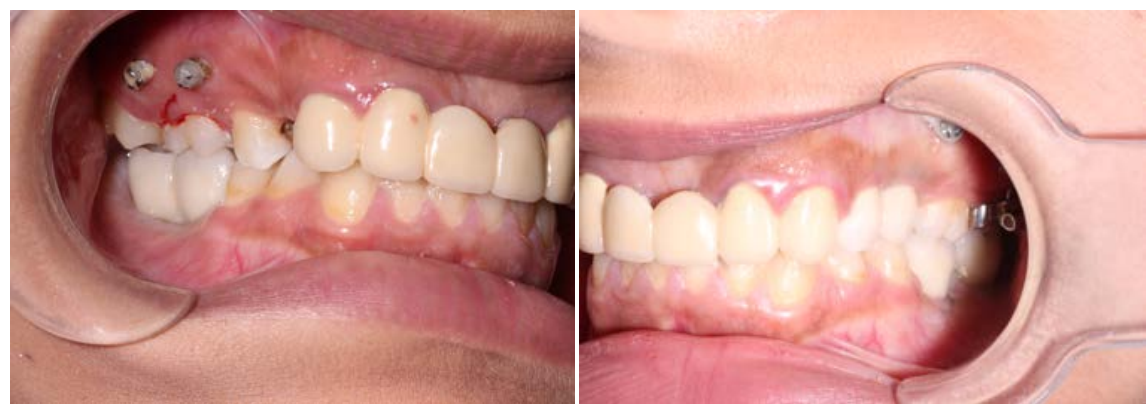

Figure 9. Restoration with ceramic crowns.

over erupted teeth is orthodontic intrusion with the aid of orthodontic mini screws [4].

In order to intrude the supra-erupted maxillary molars, mini screws were placed in the buccal dento-alveolus between the first and second permanent molars \& between the second premolar and first permanent molar just below the level of the muco-gingival junction. In order to insure bodily molar intrusion without buccal flaring, trans-palatal bars were extended between the maxillary first permanent molars and between the maxillary second permanent molars. Trans-palatal bars were chosen instead of palatal mini screws just in order to avoid injury of the greater palatine nerve and artery during palatal mini implant insertion. Mini implants were loaded two weeks following their placement although most of the evidence in the literature indicates no difference in the failure rate between immediate and delayed mini implant loading [7]. Since it is well known that the inter radicular area between the second premolar and first permanent molar is a very suitable site for mini implant placement (large inter radicular distance and the good bone quality there) no screw loosening was reported during the orthodontic loading process [8] [9].

At the end of treatment, the mini screw intrusion method together with the placement of Osseo-integrated implants at the lower permanent molar sites were able to reestablisha stable and functional occlusion for the patient.

\section{Conclusion}

In the past, management of over erupted permanent maxillary molars posed a clinical problem for the dentists. But nowadays, they are no longer a problem since they can be successfully intruded with the help of orthodontic mini screws and sectional orthodontic appliances. Maxillary molar intrusion and the placement of mandibular implant supported prosthesis enabled the establishment of functional posterior occlusion.

\section{Acknowledgements}

We thank Dr. Reyadjaradat for documenting the case photographically.

\section{Conflicts of Interest}

The authors declare no conflicts of interest regarding the publication of this paper. 


\section{References}

[1] Sudhindra, M., Shivakumar, N.P., Arvind, M., Ramesh, Ch. and Baswakumar, M. (2010) Management of Supra-Erupted Posterior Teeth: A Review. International Journal of Dental Clinics, 2, 27-30.

[2] Creekmore, T. and Eklund, M. (1983) Possibility of Skeletal Anchorage. Journal of Clinical Orthodontics, 17, 266-267.

[3] Armbruster, P., Sheridan, J.J. and Nguyen, P. (2003) An Essix Intrusion Appliance. Journal of Clinical Orthodontics, 37, 412-416.

[4] Kravitz, N.D., Kusnoto, B., Tsay, T.P. and Hohlt, W.F. (2007) The Use of Temporary Anchorage Devices for Molar Intrusion. Journal of the American Dental Association, 138, 56-64. https://doi.org/10.14219/jada.archive.2007.0021

[5] Erverdi, N., Keles, A. and Nanda, R. (2004) The Use of Skeletal Anchorage in Open Bite Treatment: A Cephalometric Evaluation. The Angle Orthodontist, 74, 381-390.

[6] Ingle, J. and Glick, D. (2002) Differential Diagnosis and Treatment of Dental Pain. Endodontics, 4, 524-549.

[7] Jiang, X.H., Zhang, Y., Han, X., Liu, J.H. and Ma, T.C. (2008) Histological Observation of Microscrews Anchorage Implant-Bone Interface Loaded with Different Orthodontic Condition. Shanghai Journal of Stomatology, 17, 621-624.

[8] Chaimanee, P., Suzuki, B. and Suzuki, E.Y. (2011) Safe Zones for Mini Screw Implant Placement in Different Dentoskeletal Patterns. The Angle Orthodontist, 81, 397-403. https://doi.org/10.2319/061710-111.1

[9] Mohammed, H., Wafaie, K., Rizk, M.Z., Almuzian, M., Sosly, R. and Bearn, D.R. (2018) Role of Anatomical Sites and Correlated Risk Factors on the Survival of Orthodontic Miniscrew Implants: A Systematic Review and Meta-Analysis. Progress in Orthodontics, 19, 36. https://doi.org/10.1186/s40510-018-0225-1 